\title{
Grupos de convivência como suporte ao idoso na melhoria da saúde
}

\author{
Companionship groups as support to improve the health of the elderly
}

Francisca Maria Assmann Wichmann'

Analie Nunes Couto ${ }^{1}$

Silvia Virgínia Coutinho Areosa²

Maria Concepción Menéndez Montañés ${ }^{3}$

\section{Resumo}

O estudo buscou conhecer a representação da população idosa sobre o grau de satisfação, quanto aos benefícios obtidos na melhoria da saúde, com a convivência em grupos. As redes de relações são importantes fontes de suporte social e satisfação com a vida. Considerou o grau de satisfação como um dos indicadores de bem-estar no envelhecimento com qualidade de vida, descrevendo o nível de satisfação na participação social de idosos da Espanha e do Brasil que se filiam a grupos/centros de convivência. A população em estudo foi composta por 262 idosos do Brasil e 262 idosos da Espanha que faziam parte de grupos/centros de convivência onde as universidades tinham inserção. O corpus da pesquisa, arquivado no banco de dados do grupo de pesquisa em Envelhecimento da UNISC, se baseou nas narrativas dos idosos entrevistados, que refletem a visão deles sobre a participação em grupos de convivência e suas experiências pessoais. A análise qualitativa das entrevistas foi realizada por meio da técnica da análise de conteúdo. Pode-se observar que as relações sociais e o suporte social, sendo este emocional, instrumental ou informacional, favorecem a melhora da saúde. As atividades mais comentadas e realizadas pelos idosos, do Brasil e da Espanha, são as relacionadas à sociabilidade, expressas no contato com os amigos, ocasião em que buscam compartilhar alegrias, tristezas e conhecimentos.

\section{Abstract}

This study aimed to know the representation of the elderly population about the degree of satisfaction with benefits obtained in health improvement within companionship groups. Relationship nets are important sources of social support and satisfaction with life. It considered satisfaction levels as welfare indicator in aging with quality of life,

\footnotetext{
Departamento de Educação Física e Saúde. Universidade de Santa Cruz do Sul. Santa Cruz do Sul, RS, Brasil.

2 Departamento de Psicologia, Programa de Mestrado e Doutorado em Desenvolvimento Regional. Universidade de Santa Cruz do Sul. Santa Cruz do Sul, RS, Brasil.

3 Departamento de Psicologia Evolutiva e da Educação. Universidade de Barcelona. Barcelona, Espanha.
}

Apoio financeiro: Universidade de Santa Cruz do Sul - UNISC, CNPq (edital Universal e PIBIC) e FAPERGS (ARD e BIC). Edital MCT/CNPq 14/2009 Universal - faixa B - processo: 470625/2009-0.

Correspondência / Correspondence

Francisca Maria Assmann Wichmann

E-mail: francis@unisc.br
Palavras-chave: Envelhecimento. Saúde. Qualidade de Vida. Socialização. 
describing the satisfaction level in social participation of elderly in Spain and in Brazil that are affiliated to companionship centers/groups. The study population included 262 elderly people in Brazil and 262 in Spain that were part of companionship centers/ groups where the universities had insertion. The research corpus, archived in the UNISC Aging research group database, was built from narratives made by the interviewed elderly, reflecting their view of their participation in companionship groups and their personal experiences. The qualitative analysis of interviews was performed through the content analysis technique. It has been observed that social relationships and social support, being emotional, instrumental or informational, favor health improvement. The activities that have been most commented and performed by the elderly, in Brazil and Spain, are the ones related to sociability, shown in the contact with friends, when joys, sorrows and knowledge are shared.
Key words: Aging. Health. Quality of Life. Socialization.

\section{INTRODUÇÃO}

A população de idosos no mundo tem aumentado consideravelmente nas últimas décadas. Esse aumento na sobrevida se deve aos avanços da medicina moderna, que melhoraram as condições de saúde e reduziram a mortalidade. Os dois processos, responsáveis pelo aumento da longevidade, foram resultado de políticas e de incentivos na área da saúde e de um grande processo tecnológico. Ao mesmo tempo, surge a necessidade de garantir aos idosos não apenas maior longevidade, mas também felicidade, qualidade de vida e satisfação pessoal. ${ }^{1,2}$

A principal característica do envelhecimento saudável é a capacidade de aceitar as mudanças fisiológicas decorrentes da idade, sendo que as doenças e limitações não impossibilitam a experiência pessoal de velhice bem-sucedida. O bem-estar subjetivo é um critério essencial para a velhice bem-sucedida, aproxima-se de um princípio organizacional para alcance de metas, expandindo-se em um continum multidimensional, que ultrapassa a objetividade da saúde física. ${ }^{3}$

Entende-se a saúde como um estado em que existe uma situação ótima de bem-estar físico, mental e social, e não como a ausência de doença. Esta definição tem grande importância, pois incide num aspecto tão relevante como é avaliação das circunstâncias pessoais, sociais e culturais, junto com a avaliação das eventuais alterações físicas e mentais. Este enfoque multidimensional da saúde parece o melhor modo de se referir ao envelhecimento satisfatório/ ativo, que a proposta da ONU desenvolve em três pontos: a) prevenção da deterioração física e psíquica e promoção da saúde; b) incremento da oferta educativa e cultural; e c) integração social das pessoas idosas. ${ }^{4}$

Na Europa, satisfação e bem-estar são temas centrais na investigação do envelhecimento. A satisfação com a vida é um constructo no estudo psicossocial do envelhecimento e pode ser avaliada por meio de questões simples ou de itens escalares. Está relacionada ao modo e aos motivos que levam as pessoas a viverem suas experiências de vida de maneira positiva, refletindo em parte o bem-estar subjetivo. Da mesma forma, o bemestar subjetivo pode ser percebido e autoavaliado por meio de experiências individuais, por afetos positivos que se sobressaem aos negativos, por meio de questões simples se a pessoa se sente feliz ou infeliz, ou ainda pela satisfação global com a vida, relacionada à saúde, ao trabalho e à independência, por meio de comparações pessoais a partir de referências do próprio passado e do bem-estar de indivíduos na mesma faixa etária. ${ }^{1-5}$

O avanço da idade e a chegada da aposentadoria têm mobilizado os idosos a explorarem outros campos de desejos, anseios, projetos antes adormecidos, além de compartilharem suas experiências e saberes. Nos últimos anos, no Brasil, tem crescido o número de universidades 
e grupos de convivência da terceira idade, que promovem a redefinição de valores, atitudes e comportamentos dos idosos. ${ }^{6}$

Os grupos de convivência têm sido uma alternativa estimulada em todo o Brasil. De maneira geral, inicialmente os idosos buscam, nesses grupos, melhoria física e mental, por meio de exercícios físicos. Posteriormente, as necessidades aumentam, e as atividades de lazer, como viagens, também ganham espaço, além do desenvolvimento de outras atividades, sempre promovendo atividades ocupacionais e lúdicas. A percepção de uma boa qualidade de vida está diretamente interligada com a autoestima e ao bem-estar, e esses fatores estão associados à boa saúde física e mental, a hábitos saudáveis, a lazer, à espiritualidade e principalmente à manutenção da capacidade funcional do indivíduo.?

Neste sentido, os grupos de convivência são uma forma de interação, inclusão social e uma maneira de resgatar a autonomia, de viver com dignidade e dentro do âmbito de ser e estar saudável. Segundo Almeida et al., ${ }^{8}$ os grupos de convivência estimulam o indivíduo a adquirir maior autonomia, melhorar sua autoestima, qualidade de vida, senso de humor e promover sua inclusão social. Este fator influencia bastante a continuidade dos idosos nos programas e nas mudanças positivas que ocorrem em suas vidas. Diante disso, seleciona-se, como objeto deste estudo, a representação da população idosa em relação ao grau de satisfação, quanto aos benefícios obtidos na melhoria da saúde, com a convivência em grupos.

\section{METODOLOGIA}

O estudo foi realizado no período de 2009 a 2011, e contemplou uma abordagem qualitativa psicossocial, foco principal do estudo, uma vez que esta possibilita maior aproximação com o cotidiano e as experiências vividas pelos próprios sujeitos. ${ }^{9}$

Foram adotados e seguidos os princípios éticos dispostos na Resolução no 196/96, do Conselho
Nacional de Saúde, com aprovação do Comitê de Ética em Pesquisa com Seres Humanos da Universidade de Santa Cruz do Sul (UNISC), registrado sob o CAAE no 0023.0.109.000-09.

A população em estudo abrangeu todos os idosos com 60 anos de idade ou mais que frequentavam serviços ligados à Universidade de Santa Cruz do Sul e grupos de convivência para terceira idade onde a universidade tem inserção, assim como centros/grupos ligados à Universidade de Barcelona, Espanha. Os critérios para fazer parte da amostra nos dois países foram ter mais de 60 anos, participar de algum grupo/ centro de convivência para terceira idade e possuir condições cognitivas para responder à entrevista.

A amostra brasileira foi constituída com base no cadastro dos grupos e serviços da UNISC que atendem a idosos. No total são 23 grupos de convivência para a terceira idade, três grupos de autocuidado e três grupos de atividades físicas que são assistidos pela universidade. Nos grupos são oferecidas atividades que contemplem hábitos saudáveis e favoreçam o bem-estar (oficinas de memória, relaxamento, oficina culinária para hipertensos e diabéticos, higiene postural, oficinas de ginástica, conferências, seminários, jornadas, entre outros). Os coordenadores de grupos foram contatados no Fórum do Envelhecimento realizado no SESC Santa Cruz do Sul e por meio dos coordenadores de serviços e grupos da UNISC, sobre a disponibilidade em participar deste estudo e posteriormente para o agendamento da coleta de dados com os idosos que concordaram em participar da pesquisa.

$\mathrm{Na}$ Espanha, o grupo de pesquisa realizou o trabalho como parte da aprendizagem da matéria Psicologia Evolutiva e da Educação, em 57 centros e espaços de idosos municipais, 16 centros de idosos da Generalitat de Catalunya, 10 clubes Catalunya Caixa, 16 espaços de pessoas idosas da Fundação La Caixa, além de inúmeros centros paroquiais não quantificados, que desenvolvem atividades junto à Igreja Católica. As atividades sociais e culturais oferecidas nesses locais propiciam o encontro, a relação, a participação e a ocupação do tempo 
livre das pessoas idosas. A seleção da amostra da Universidade de Barcelona realizou-se de acordo com as condições que se definiram para que cada entrevistador(a) tivesse a possibilidade de conhecer diferentes gêneros e contextos.

Todos os locais foram comunicados formalmente sobre a finalidade da pesquisa e uma carta de autorização foi assinada pelos responsáveis legais das instituições participantes da pesquisa, tanto no Brasil como na Espanha. Os sujeitos foram informados sobre a garantia da privacidade e sigilo das informações. Todos os entrevistados assinaram o Termo de Consentimento Livre e Esclarecido. Para a seleção da amostra, utilizou-se a amostragem não probabilística por cotas, equitativas entre sexo, faixa etária e estado civil.

Após todos os critérios de seleção e validação da amostra, das 1.020 entrevistas realizadas, 496 foram eliminadas por não conterem os dados sociodemográficos ou não terem a qualidade de conteúdo requerida. Foram consideradas 524 entrevistas, sendo 262 no Brasil e 262 na Espanha. Esses critérios foram organizados e sistematizados no programa SPSS (Statistical Package for Social Science).

O instrumento de coleta de dados, utilizado e validado pela Universidade de Barcelona, está publicado em uma coleção de $\operatorname{textos}^{10} \mathrm{e}$ foi traduzido pelos pesquisadores brasileiros para ser utilizado na população do Brasil. Para a realização das entrevistas, as perguntas e orientações foram claras e precisas, bem como as condições para a seleção dos sujeitos.

Ao longo dos anos de 2009 e 2010, foram realizadas coletas de dados por alunos, professores e funcionários colaboradores, treinados pelo coordenador da pesquisa. As entrevistas foram realizadas e gravadas com o consentimento dos idosos nas dependências físicas dos grupos. Diante dos resultados apresentados nas entrevistas, foi realizada a apreciação dos dados por meio de uma análise de conteúdo que, segundo Minayo, é o termo mais usado para se referir ao tratamento dos dados de uma pesquisa qualitativa, permitindo diferenciar categorias conforme as respostas de cada entrevistado. $\mathrm{O}$ corpus da pesquisa, disponível no banco de dados do grupo de pesquisa em Envelhecimento da UNISC, foi construído a partir das narrativas dos idosos entrevistados, que refletem a visão deles sobre a participação em grupos de convivência e suas experiências pessoais.

A análise qualitativa das entrevistas iniciouse em 2011 e foi feita manualmente por meio da técnica da análise de Bardin, ${ }^{11}$ que se define como um "conjunto de técnicas de análise das comunicações", apostando no rigor do método como forma de não se perder na heterogeneidade de seu objeto. Nascida de uma longa tradição de abordagem de textos, essa prática interpretativa se destacou, a partir do início do século XX, pela preocupação com recursos metodológicos que validem suas descobertas.

O material coletado foi lido com a finalidade de se encontrar aquilo que parecesse ser mais significativo dentre as respostas das entrevistas, agrupando-as em temas ou perspectivas de investigação, escolhidas a partir de categorias de análise concernentes ao referencial teórico. Considerou-se o grau de satisfação como um dos indicadores de bem-estar no envelhecimento com qualidade de vida, descrevendo o nível de satisfação na participação social de idosos da Espanha e do Brasil que se filiam a grupos/ centros de convivência.

\section{RESULTADO E DISCUSSÃO}

O envelhecimento populacional é, hoje, um proeminente fenômeno mundial. As diferenças na expectativa de vida entre o Brasil e a Espanha estão diminuindo. Segundo Walter, ${ }^{12}$ a Espanha em 1940 ultrapassou o Brasil em 20\% quanto à esperança de vida, e em dados mais recentes, essas diferenças diminuíram: a Espanha segue com a maior esperança de vida (79,3 anos) e a do Brasil é apenas 6\% menor (72,4 anos). Segundo o Informe do Portal de Idosos IMSERSO, ${ }^{4}$ a população global de pessoas com mais de 65 anos na Espanha teve aumento de mais de oito vezes da população da mesma idade na última década. No Brasil, a Síntese de Indicadores 
Sociais do IBGE ${ }^{13}$ mostra, no Censo de 2010, que o percentual das pessoas com mais de 60 anos ou mais de idade passou de $9,1 \%$ para $11,3 \%$ entre os dois últimos censos.

Além disso, tanto o Censo de $2010^{13}$ no Brasil e IMSERSO/CSISDO ${ }^{4}$ acessado em 2011, mostram que a proporção da população "mais idosa”, ou seja, de 80 anos e mais, também está aumentando, alterando a composição etária dentro do próprio grupo, tanto no Brasil como na Espanha. Isso quer dizer que a população considerada idosa também está envelhecendo, e esse aumento da sobrevida se deve aos avanços da medicina e da tecnologia.

A pesquisa evidenciou forte associação entre o número de idosos masculinos participantes na Espanha (50,4\%), e no Brasil, de idosos do sexo feminino $(78,2 \%)$, revelando ainda que o perfil dos participantes brasileiros é em sua maioria composta por mulheres. Os homens que participaram no Brasil eram poucos (21,8\%) e em grande parte estavam acompanhando suas esposas. A proporção de idosos casados $(43,5 \%) \mathrm{em}$ ambos os sexos predomina na pesquisa. No Brasil, os maiores valores (positivos) eram de viúvos, divorciados, solteiros e com união estável, e na Espanha predomina uma forte relação com idosos casados $(71,4 \%)$ ao longo do período analisado.

Encontrou-se uma homogeneidade do número de casados (43,5\% brasileiros e 51,5\% espanhóis) e viúvos (40,5\% brasileiros e 41,6\% espanhóis) na distribuição dos dois países, mesmo não sendo sempre os mesmos idosos participantes. Por sua vez, evidenciou-se forte associação local na faixa etária, destacando a presença maior de idosos jovens entre 60-65 anos (25,6\%), do sexo feminino (80,2\%), solteiros e viúvos no Brasil; na Espanha, os resultados indicaram forte presença de idosos velhos acima de 76 anos e do sexo masculino (45,8\%).

$\mathrm{Na}$ participação em grupos de convivência, os idosos referiram que compartilham suas angústias, tristezas, amores, alegrias, afetos, saberes, reduzem sentimentos como medo, insegurança, depressão, sobretudo após a perda de entes queridos e membros da família, doam e recebem afeto, conversam com os amigos e trocam experiências de vida. Além disso, afirmam ser o grupo de convivência um ambiente que possibilita fazer novas e boas amizades. De maneira geral, eles associaram bem-estar à saúde mental e física.

Percebeu-se que, para os idosos, fazer parte de um grupo é uma conquista, uma forma de romper com o cotidiano das tarefas do lar e das obrigações com os filhos e netos, momento em que eles adquirem conhecimentos e desfrutam de "liberdade" durante essa fase da vida. ${ }^{14}$ Observou-se que muitos idosos alegaram que um dos motivos da participação nos grupos de convivência é sair da solidão, conviver com pessoas da mesma idade e buscar uma atividade com a finalidade de dar um sentido para a vida.

A satisfação com a vida é uma das medidas do bem-estar psicológico, que reflete a avaliação pessoal do indivíduo sobre determinados domínios. As redes de relações são importantes fontes de suporte social e estão relacionadas ao senso de bem-estar. Do mesmo modo, o nível de satisfação dos idosos na convivência com outras pessoas pode aumentar de intensidade no decorrer da vida, melhorando a qualidade de vida. Nos grupos, surge a oportunidade de estabelecer novas amizades, ampliar os conhecimentos e afastar a solidão. ${ }^{5}$

Segundo Mello, ${ }^{15}$ qualidade de vida relacionada com saúde e estado subjetivo de saúde são conceitos afins, necessariamente ligados ao impacto do estado de saúde sobre a capacidade de o indivíduo viver plenamente, e centrados na avaliação subjetiva do paciente. Em termos de saúde, uma questão muito presente nos estudos de Gerontologia é a qualidade de vida ou sobrevida dos idosos. ${ }^{16}$

Conforme afirmam Lima, Silva \& Galhardoni, ${ }^{17}$ na prática profissional gerontológica não é raro encontrar idosos que fazem referência a altos níveis de satisfação com a vida e bem-estar subjetivo, embora com níveis intermediários de dependência. Referem ainda que a própria experiência do envelhecimento é adaptativa, ou seja, os indivíduos com algum grau de limitação podem se adaptar e 
apresentar outros padrões de avaliação sobre envelhecimento bem-sucedido.

A melhoria da saúde é refletida na dimensão da satisfação com o bem-estar físico e emocional relativo especificamente aos hábitos saudáveis. A qualidade relacionada à saúde está se transformando em indicador relevante do bemestar, sendo útil para avaliar as necessidades de saúde e, ao mesmo tempo, predizer de forma consistente a sobrevida dessa população. Joia, Ruiz \& Donalisio ${ }^{1}$ encontraram em seu estudo, como fator mais importante relacionado à melhoria da saúde entre idosos de Botucatu$\mathrm{SP}$, estar satisfeito com as atividades de vida diária. Para os autores, esses dados corroboram a afirmativa de que a capacidade funcional - ou autonomia - é um indicativo da satisfação com a saúde e com a própria vida.

[...] to satisfeita porque faz bem pra mim, eu tinha problema de pressão e tudo isso ta passando, isso ajuda muito a gente (mulher, 60 anos, casada, idosa brasileira).

[...] ali me ajudam a recuperar a memória, e assim não perco mais do que tenho (homem, 82 anos, casado, idoso espanhol).

Catalan ${ }^{18}$ e Garcia $^{19}$ referem, em sua pesquisa sobre o estado de saúde subjetivo, que 39,7\% dos idosos percebem sua saúde como boa ou muito boa, com relação a $75,9 \%$ do resto da população. O presente estudo revela que essa percepção subjetiva de saúde piora com a idade, além de apresentar resultados diferentes entre mulheres e homens idosos. Enquanto 48,5\% dos homens avaliam sua saúde como boa ou muito boa, $33 \%$ das mulheres a consideram da mesma forma. ${ }^{18} \mathrm{E}$ possível que essa visão subjetiva tenha relação com seu estado de saúde real.

As questões de saúde levam sem dúvida à avaliação das possíveis incapacidades que se associam ao processo de envelhecimento. Segundo dados da Pesquisa Europeia de Saúde na Espanha do IMSERSO, ${ }^{4} 10,3 \%$ das mulheres de 65 a 74 anos e $25,2 \%$ das mulheres de mais de 75 anos apresentam graves limitações como consequência de seus problemas de saúde. No caso dos homens, os dados são muito diferentes: $7 \%$ e $17,6 \%$, respectivamente, em pessoas da mesma idade. Em termos gerais, há a possibilidade de que, com o processo de envelhecimento, exista algum tipo de disfuncionalidade com o aumento da idade. Aos 80 anos, mais da metade dos espanhóis têm problemas objetivos para realizar as atividades da vida diária. ${ }^{4}$ Segundo dados do IMSERSO ${ }^{4}$ é mais alta a frequência em pessoas com alto índice de analfabetismo, em viúvos e os que vivem em lares diferentes (distintos dos unipessoais, multigeracionais e conjugais). A Pesquisa de Incapacidades, Autonomia Pessoal e Situações de Dependência ${ }^{4}$ evidencia que se reforça a tendência desses dados, pois é evidente que as taxas de incapacidade mostram um perfil muito diferente segundo o sexo.

Segundo a Pesquisa do Emprego do Tempo, ${ }^{4}$ metade das pessoas idosas de 65 anos diz realizar atividades esportivas ao ar livre. Evidenciam-se diferenças por gêneros nessa questão. Este tipo de atividade é mais habitual em homens do que em mulheres (seis homens para quatro mulheres), variando também o tempo que cada grupo emprega para tais atividades (2h12min para os homens contra $1 \mathrm{~h} 35 \mathrm{~min}$ para as mulheres). Por outro lado, 9,66\% dos homens de 65 a 74 anos e 25,5\% dos idosos de mais de 75 anos declaram não realizar nenhum tipo de atividade. A porcentagem é maior no caso das mulheres (15,5\% das mulheres de 65 a 74 anos e $35,2 \%$ das mulheres com mais de 75 anos).

As formas de envelhecimento também são influenciadas pela educação. $O$ nível de instrução das pessoas idosas influi diretamente nas condições de vida, de convivência, na idade da aposentadoria, nas condições econômicas e, evidentemente, nos estados de ânimo para enfrentar os desafios da vida diária. ${ }^{4}$

Os entrevistados deste estudo mencionaram a busca por melhores condições de saúde como uma das razões que os levam a participar de grupos de convivência. Outra razão mencionada se refere à necessidade do convívio social, característica de todo ser humano de estar inserido num grupo social, no qual possa interagir com outras pessoas, o que pode ser visualizado nas categorias que apareceram na tabela 1. 
Tabela 1 - Percepção dos benefícios obtidos na participação em grupo/centro e nas atividades realizadas. Santa Cruz do Sul-RS e Barcelona, Espanha, 2009-2011.

\begin{tabular}{lcccc}
\hline \multicolumn{1}{c}{ Categorias } & \multicolumn{2}{c}{ Brasil } & \multicolumn{2}{c}{ Espanha } \\
& $\mathrm{n}$ & $\%$ & $\mathrm{n}$ & $\%$ \\
\hline Socialização & 118 & 45 & 127 & 48,5 \\
Melhora a saúde física e mental & 120 & 45,8 & 66 & 25,2 \\
Amplia o conhecimento & 10 & 3,9 & 22 & 8,4 \\
Visão negativa & - & 0 & 6 & 2,3 \\
Não respondeu & 14 & 5,3 & 41 & 15,6 \\
Total & 262 & 100 & 262 & 100 \\
\hline
\end{tabular}

Os idosos do Brasil referiram melhoria das condições de saúde $(45,8 \%, \mathrm{n}=120)$ e aumento da socialização $(45 \%, \mathrm{n}=118)$ como principais benefícios. Verifica-se que um dos motivos que os levaram a frequentar os grupos de convivência no Brasil é a melhoria da qualidade de vida, nos aspectos referentes à saúde, buscando aumentar o período de vida ativa, prevenindo perdas funcionais e recuperando capacidades. Já os idosos da Espanha referiram a socialização (48,3\%, $\mathrm{n}=127$ ) como o fator de maior importância, seguido da melhora da saúde $(25,2 \%, n=66)$. Muitos idosos no Brasil participam de grupos ligados a atividades físicas, esportes, na busca da melhora da saúde. Isto pode ser percebido na fala das idosas brasileiras:

Muito pra tudo, [...] na saúde. Ajuda na depressão e na saúde total" (mulher, casada, 65 anos).

Muito importante, porque pra mim ajudou muito as atividades, eu já era quase aleijada, e agora está bem melhor (mulher, casada, 68 anos).

Essa percepção sobre o benefício também pode ser verificada na fala de um idoso espanhol:

Valorizo porque tenho colegas ali, que me distraio com eles e falamos, e fazemos exercicios e fazemos coisas e tudo isso me serve para estar entretido e não metido em casa e assim tenho um porquê nesta vida (homem, casado, 82 anos).
Para eles, no entanto, a primeira opção pela escolha do grupo é o convívio social, as relações de amizade que estabelecem nos grupos. Em relação à percepção positiva na convivência em grupos, 95\% ( $\mathrm{n}=248)$ dos idosos entrevistados no Brasil e 82,1\% ( $\mathrm{n}=215)$ na Espanha dizem que os grupos são os lugares de realização, são espaços de promoção do bem-estar social, de construção da confiança e do equilíbrio pessoal. E, ao mesmo tempo, da melhoria na autoestima, na vontade de viver e na capacidade de enfrentar problemas.

$\mathrm{Na}$ visão dos idosos, a saúde não é percebida como ausência total de enfermidades ou como fruto da comparação da situação presente com um padrão ideal, mas vista como uma avaliação ligada a expectativas sobre o que esperar da velhice. A autoavaliação da saúde, com o passar dos anos, não se deteriora porque os idosos avaliam a saúde como boa quando ela é suficiente para viver. ${ }^{20}$

No estudo realizado por Cupertino, Rosa \& Ribeiro, ${ }^{21}$ foi examinada a definição de envelhecimento saudável em uma amostra de 501 idosos com idade entre 60 e 93 anos da comunidade, buscando identificar as multidimensões percebidas pelos mesmos e realizada análise de conteúdo das respostas abertas sobre envelhecimento saudável. Neste estudo foram identificadas 29 categorias, sendo as mais citadas: saúde física, saúde social e saúde emocional. 
Ter um grupo de referência propicia ao idoso um suporte emocional e motivação para que este indivíduo tenha objetivos em sua vida e possa compartilhar alegrias, tristezas e conhecimentos. Os contatos sociais permitem engajamento social, que também é uma forma de vivenciar o desenvolvimento na idade adulta de maneira bemsucedida. $\mathrm{O}$ apoio social deve ser compreendido como uma experiência pessoal e subjetiva que leva a um maior senso de satisfação com a vida. Silva et al. $^{22}$ sugerem que existe uma relação entre apoio social e uma variedade de medidas dependentes: saúde, adaptação psicológica, percepção de bem-estar, redução do mal-estar, longevidade e mortalidade, satisfação com a vida, entre outros. Isto pode ser observado nas falas:

Sim, porque assim me distraio, já que em casa somente olho a televisão e tem horas que estou aborrecida. Em troca, se venho aqui no centro, me distraio, faço amigos e jogo (mulher, viúva, 84 anos, entrevistada na Espanha).

Sim, é muito importante, a gente tem bastante amigos, faz as ginásticas. É muito bom (mulher, casada, 68 anos, idosa brasileira).

A experiência do envelhecimento bemsucedido valoriza a percepção dos próprios idosos, sendo que são protagonistas de intervenções e dotados de julgamentos sobre bem-estar e qualidade de vida. ${ }^{17}$ Nesse convívio, o idoso troca experiências e interage com outras pessoas, fortalecendo as relações de apoio. $\mathrm{O}$ apoio ou suporte social, manifestado por meio de redes sociais e relações íntimas, também permite satisfazer necessidades em situações cotidianas e de crise, sendo muito importante para sua adaptação no processo em que acontecem as perdas. Tais recursos são promovidos, apoiados ou colocados nos espaços de relações sociais significativas, mediante o acesso a vínculos sociais compensatórios que protegem os idosos de sentimentos negativos derivados das perdas. ${ }^{23}$

Os idosos encontram nos grupos um espaço de possibilidades de partilhar as experiências pessoais, suas incertezas e suas angústias, permitindo uma avaliação do seu viver. Nesse convívio social surge a oportunidade de compartilhar aprendizagens e vivências, apreciando os problemas em grupo, ${ }^{24,25}$ como se percebe na fala seguinte:

Sim, porque venho todas as manhãs e, além disso, fir. aqui amigos de diferentes idades, e nós contamos nossos problemas, conversamos, fazemos brincadeiras, rimos e passamos bem (homem, viúvo, 82 anos).

Esta fala de um idoso espanhol demonstra a importância dos grupos como uma rede de suporte social. O apoio advindo dos grupos sociais contribui com a saúde mental e o bemestar psicológico. É um preditor significativo dos recursos pessoais de enfrentamento dos problemas, e está inversamente correlacionado com depressão, estresse e sintomatologia física, associando-se com a redução de riscos de mortalidade, ${ }^{23}$ conforme os entrevistados a seguir:

Sim, é uma maneira de ter amigos, conhecer gente, estar um tempo ocupada e não pensar em nada, desconectar (mulher, casada, 72 anos, entrevistada espanbola).

Estou satisfeita, [...] Porque faz bem pra mim, en tinha problema de pressão e tudo isso está passando, isso ajuda muito a gente (mulher, casada, 60 anos, entrevistada brasileira).

Segundo Almeida et al., ${ }^{8}$ há uma correlação negativa entre a participação em atividades sociais e os sintomas de depressão, ou seja, quanto mais amigos e mais atividades sociais, menor a sintomatologia depressiva. A socialização promovida pela participação no grupo de convivência pode ser uma explicação para a menor frequência de indivíduos com depressão.

No estudo realizado por Yokoyama, Carvalho \& Vizzotto, ${ }^{20}$ com 10 homens e 20 mulheres de idade entre 60 e 82 anos, frequentadores de um centro de referência do ABC Paulista, o estado emocional positivo apareceu em $29,3 \%$ das respostas da amostra, percentual maior entre as mulheres, que demonstraram maior preocupação com o bem-estar subjetivo. Este indicador está relacionado aos sentimentos e emoções agradáveis, isto é, aos aspectos psicológicos ou subjetivos, sendo indicador importante de qualidade de vida. 
O envelhecimento saudável e socialmente engajado é reconhecido como um dos maiores preditivos da velhice bem-sucedida. Segundo Mello $^{15}$ e Francisco, ${ }^{26}$ os estudiosos de gerontologia social investigaram o engajamento social dos idosos e os modelos conceituais sobre os relacionamentos entre idosos e sociedade. ${ }^{15,26}$ Com isso surgiram as teorias sociais que tentam abrir caminhos para compreender as relações sociais e o engajamento social na velhice. Nesse contexto, a subjetividade tende a ser um bom indicador de qualidade de vida, pois permite avaliar em que medida a velhice pode ser percebida como uma etapa bem-sucedida da vida. ${ }^{15}$

O depoimento de um idoso brasileiro mostra esta satisfação:

É importante, porque ao invés da pessoa velha se sentir velha e ficar acomodada em quatro paredes em casa, assim, entra em contato com outras pessoas e socialmente se realiza mais (bomem, casado, 82 anos).

Foi possível observar, no desenvolvimento desta pesquisa, que as relações sociais e o suporte social, sendo este emocional, instrumental ou informacional, são de grande importância em todos os momentos da vida. As atividades mais comentadas e realizadas pelos idosos, do Brasil e da Espanha, são as relacionadas à sociabilidade, expressa no contato com os amigos. Essa forma de lazer é muito importante na medida em que reduz o estresse, a ansiedade e a depressão, assim como proporciona o desenvolvimento do espírito crítico das pessoas com 60 anos ou mais. ${ }^{22} \mathrm{~A}$ fala de um idoso espanhol reflete bem isso, como se pode constatar:

Sim, é importante, porque me distraio, converso com os amigos, conversamos sobre a imprensa, sobre futebol, jogamos umas partidas de cartas, de dominó, bastante coisas (homem, casado, 71 anos).

Na concepção dos entrevistados, o isolamento determina a depressão no idoso. Os depoimentos revelaram a necessidade de se manterem inseridos socialmente, pois envelhecer de maneira saudável é não ter apenas uma boa saúde, mas são vários fatores que contribuem para se sentirem ativos. Os grupos podem funcionar como rede de apoio que mobiliza as pessoas na busca de autonomia, na melhora da autoestima, na resiliência e diminuindo a vulnerabilidade. No convívio entre pessoas, criam-se vínculos que possibilitam a inclusão social. ${ }^{19}$

Os idosos expuseram que o conteúdo trabalhado nas atividades estimula a participação, o que torna oportuno fazer o que gosta e, ao mesmo tempo, trabalha a saúde como um todo. No Brasil, os idosos destacaram que o conteúdo trabalhado promoveu o bem-estar social, beneficiando uma melhora em sua saúde, como se verifica nas falas de entrevistados da amostra brasileira:

\begin{abstract}
Sim, ajuda muito a água e as atividades. Se não venho uns dias sinto falta, en tenho diabete e pressão alta e as atividades me ajudam (mulher, casada, 62 anos).
\end{abstract}

É muito importante porque nesse grupo a gente faz. muitas atividades, dança principalmente e aprende muita coisa também sobre saúde [...] em casa a gente não tem isso (mulher, divorciada, 62 anos).

Na busca de obter melhorias na saúde, os grupos proporcionam aos idosos, por meio de palestras educativas sobre alimentação saudável e prática de exercícios físicos, mudanças no estilo de vida, repercutindo na melhoria da sua saúde e, ao mesmo tempo, contribuindo para a realização dos afazeres da vida diária.

Segundo Bassoli \& Portella, ${ }^{24}$ as novas aprendizagens promovidas pela educação formal e informal têm sido um dos numerosos argumentos tidos pela Gerontologia como importante recurso para manter a funcionalidade, a flexibilidade e a possibilidade de adaptação dos idosos. Da mesma forma, a prática de exercícios físicos, as oficinas e as palestras educativas ajudam os idosos a se manterem fortalecidos no enfrentamento das atividades diárias, como demonstra a fala de uma idosa brasileira:

Uma por causa do controle da saúde, porque a gente acha que come certo, que se alimenta certo, mas não, e é importante porque a gente já tem mais idade e começa a comer coisas que não estão certas, e aqui eu vim ter aquela experiência de ter uma boa alimentação (mulher, viúva, 73 anos). 
Os idosos relataram que as atividades estimulam o diálogo entre pares por meio de palestras e valorizam suas experiências de vida. Considerando as obrigações profissionais, conjugais e sociais presentes na vida de qualquer indivíduo, a falta de tempo para o lazer e dedicação à saúde é fato, sendo a reversão dessa falta de tempo essencial para a obtenção de qualidade de vida, aliada ao bem-estar físico. ${ }^{25}$

Do mesmo modo, Sposito et al. ${ }^{5}$ referem que preditores objetivos influenciam no bem-estar subjetivo, entre eles a saúde percebida, além dos aspectos subjetivos (percepção). Estes também envolvem uma interação de variáveis, tais como a comparação da sua saúde com a de outras pessoas da mesma idade e das expectativas da velhice, as consequências das doenças sobre seu bemestar e sobre as atividades que o idoso consegue realizar. A queda da capacidade funcional ou da funcionalidade do idoso, evidentemente, exerce expressiva redução no bem-estar subjetivo, como se observa na fala deste idoso espanhol:

Pois sim, porque ali me ajudam a recuperar a memória, e assim não perco mais do que tenho (homem, casado, 82 anos).

Estudo realizado em Botucatu-SP, relacionado à satisfação com a saúde entre idosos, indicou que a autonomia para o exercício das atividades da vida diária reflete o que mais se aproxima do que os entrevistados consideram saúde. ${ }^{1}$ Sendo este o fator mais importante, estar satisfeito com as atividades da vida diária é um indicativo de que a satisfação com a saúde e com a própria vida está relacionada com a capacidade funcional ou autonomia, uma vez que, quanto mais ativo o idoso, maior sua satisfação com a vida e, consequentemente, melhor sua qualidade de vida.,15

Verificou-se que, na concepção dos idosos, os aspectos relacionados à prática de exercícios físicos, como caminhada e hidroginástica, podem melhorar a qualidade de vida das pessoas. Para eles, o autocuidado, por meio da prática de atividade física e da melhoria da alimentação, ajuda a diminuir os riscos de complicações de doenças preestabelecidas. Com o envelhecimento ocorrem alterações orgânicas, reduzindo a capacidade do idoso de realizar atividades cotidianas. ${ }^{15}$ Entretanto, ao frequentarem grupos de convivência, os idosos apontaram que houve mudanças significativas em relação a sua saúde.

O fator físico, considerado um dos indicadores de satisfação com a vida, tem mostrado a importância na avaliação que o indivíduo faz da própria vida. A manutenção da capacidade funcional, por estar relacionada com a capacidade de ocupar-se com o trabalho e/ou com atividades agradáveis até idades mais avançadas, tem importantes implicações na qualidade de vida de idosos. Da mesma forma, o bem-estar na velhice resulta do equilíbrio entre as limitações e potencialidades dos idosos, permitindo que venham a lidar com as perdas ocorridas com o envelhecimento. ${ }^{15,26-28}$

O nível de satisfação com as atividades possibilita a integração social e ao mesmo tempo melhora a qualidade de vida, pois favorece a adoção de hábitos saudáveis e, consequentemente, um envelhecer com qualidade e vida produtiva. Esse processo destacou-se principalmente entre os idosos da Espanha, como se observa nas falas:

\section{Sim, porque eu gosto, me sinto mais jovem e mais independente (mulher, viúva, 93 anos).}

Todas as atividades são positivas na nossa idade, pois melhoram a saúde, a memória, muita coisa (homem, casado, 65 anos).

Para os idosos, participar não significa somente usufruir as atividades, mas também trabalhar coletivamente, incluir-se nas discussões e proposições de alternativas, no planejamento de ações, na concretização de planos, no controle e na avaliação das atividades. $\mathrm{O}$ envolvimento comunitário pode ser um fator significativo para melhorar a percepção da confiança pessoal e a satisfação em viver.

A busca por um envelhecimento com saúde, dignidade, autonomia e independência tem sido relacionada com uma contínua participação da pessoa idosa em movimentos sociais, sejam eles econômicos, culturais, cívicos ou espirituais, 
uma vez que contribuem para a manutenção da autonomia e independência na velhice, no contexto da interdependência (familiares, amigos, vizinhos, associações, etc.) e de solidariedade entre gerações. ${ }^{15}$ Através da promoção da saúde e da prevenção de doenças, é possível buscar um envelhecimento saudável, por meio da manutenção da capacidade funcional por maior período possível. ${ }^{15}$

Diante desses fatores, percebe-se a importância que os grupos exercem na vida dessas pessoas, pois ali o idoso tem a possibilidade de encontrar estímulo para uma vida social sadia, desenvolver sua cultura e ter momentos de lazer. Melhoram-se, assim, sua autoestima e sua aceitação na sociedade, pois é nesses locais que recebem lições de cidadania, de participação e de como colaborar com o bem comum, aprendendo que para exercê-las não há limite de idade.

As limitações do estudo devem-se ao fato de ser uma amostra grande, que envolveu uma grande equipe de pesquisadores de ambos os países. A capacitação para a coleta de dados foi responsabilidade de cada coordenador de pesquisa na sua IES e envolveu contextos

\section{REFERÊNCIAS}

1. Jóia LC, Ruiz T, Donalísio MR. Grau de satisfação com a saúde entre idosos do Município de Botucatu, Estado de São Paulo, Brasil. Epidemiol Serv Saúde 2008;17(3):187-94.

2. Waldman BF. Envelhecimento bem-sucedido: uma metodologia de cuidado a pessoas com diabetes mellitus [tese de Doutorado]. Porto Alegre: Programa de Pós-Graduação em Gerontologia Biomédica da Pontifícia Universidade Católica do Rio Grande do Sul; 2006.

3. Teixeira INDAO, Neri AL. Envelhecimento bemsucedido: uma meta no curso da vida. Psicol USP 2008;19(1):81-94.

4. Instituto de Mayores y Servicios Sociales. Envejecimiento activo. Libro blanco. Madrid: IMSERSO; 2011 [acesso em 11 nov 2011]. Disponível em: http://imserso.es/InterPresent2/groups/imserso/ documents/binario/libro_blanco_ea_nov11.pdf. institucionais diferenciados. E ainda, por se tratar de um questionário em que vários aspectos são avaliados, o participante pode ser dependente para algumas atividades e para outras não, assim os próprios instrumentos podem gerar uma interpretação errônea.

\section{CONCLUSÃO}

De acordo com os resultados obtidos neste estudo, pôde-se perceber a importância de os idosos participarem de centros/grupos de convivência, integrando-se a uma rede social, o que se evidenciou pelos relatos que fizeram ressaltando sentirem-se mais satisfeitos com a vida. As mudanças, segundo os entrevistados, atingiram principalmente os fatores relacionados com a questão da saúde. Muitos relataram que, antes de frequentar os grupos, viviam com dores que os impediam de realizar atividades comuns da vida diária.

Sendo assim, as atividades proporcionadas pelos grupos auxiliaram muito para que os idosos deste estudo pudessem obter um estilo de vida mais saudável e, consequentemente, melhorar sua qualidade de vida.

5. Sposito G, Diogo MJDE, Cintra FA, Neri AL, Guariento ME, Sousa MLR. Relações entre o bem-estar subjetivo e a funcionalidade em idosos em seguimento ambulatorial. Rev Bras Fisioter 2010;14(1): 81-9.

6. Silva AO, Silva MD, Meira JBS, Ferreira GM. Envelhecimento em grupos de convivência: uma experiência no SESC - Unidade Açude Velho/ Campina Grande, Paraíba. In: XIII Encontro Latino Americano de Iniciação Científica, IX Encontro Latino Americano de Pós-Graduação e III Encontro Latino Americano de iniciação Científica. São José dos Campos: Universidade do Vale do Paraíba; [data desconhecida].

7. Sousa L, Galante H, Figueiredo D. Qualidade de vida e bem-estar dos idosos: um estudo exploratório na população portuguesa. Rev Saúde Pública [Internet] 2003 [acesso em 21 jul 2011];37(3):364-71. Disponível em: http://www.scielo.br/pdf/rsp/v37n3/15866. 
8. Almeida EA, Madeira GD, Arantes PMM, Alencar MA. Comparação da qualidade de vida entre idosos que participam e idosos que não participam de grupos de convivência na cidade de Itabira-MG. Rev Bras Geriatr Gerontol [Internet] 2010 [acesso em 11 ago 2011];13(3):435-44. Disponível em: http://revista. unati.uerj.br/pdf/rbgg/v13n3/v13n3a10.pdf.

9. Minayo MCS. O desafio do conhecimento: pesquisa qualitativa em saúde. 10 ed. São Paulo: Hucitec; 2007.

10. Montañés MCM, Sala JLC, Reverte MAO. Contextos y cambios evolutivos em la adolescência, madurez y senectud: necesidades e intervenciones educativas. Textos docents 334. Barcelona: Universitat de Barcelona; 2007.

11. Bardin L. Análise de conteúdo. Tradução Luís Antero Reto e Augusto Pinheiro. Lisboa: Edições 70; 2004.

12. Walter MIMT A dualidade na inserção política, social e familiar do idoso: estudo comparado dos casos de Brasil, Espanha e Estados Unidos. Opin Publica 2010;16(1):186-219.

13. Instituto Brasileiro de Geografia e Estatística. Síntese de Indicadores Sociais: uma análise das condições de vida da população brasileira. Estudos \& Pesquisas: informação demográfica e socioeconômica n. 27. Rio de Janeiro: IBGE; 2010 [acesso em XX mês 201X]. Disponível em: http://www.ibge.gov.br/home/estatistica/ populacao/condicaodevida/indicadoresminimos/ sinteseindicsociais2010/SIS_2010.pdf.

14. Salgado MA. Os Grupos e a ação pedagógica do trabalho social com idosos. A Terceira Idade: Estudos sobre Envelhecimento 2007;18(39):67-78.

15. Mello DB. Influência da Obesidade na Qualidade de Vida de Idosos. [tese de Doutorado]. Rio de Janeiro: Escola Nacional de Saúde Pública da Fundação Oswaldo Cruz; 2008.

16. Camarano AA. Envelhecimento da população brasileira: uma contribuição demográfica. Texto para discussão, n. 858. Rio de Janeiro: IPEA; 2002 [acesso em 2 jul 2011]. Disponível em: http://www.ipea.gov. br/portal/images/stories/PDFs/TDs/td_0858.pdf.

17. Lima AMM, Silva HS, Galhardoni R.

Envelhecimento bem-sucedido: trajetórias de um constructo e novas fronteiras. Interface (Botucatu) 2008;12(27):795-807.

18. Catalan EC, Garcia A. Un perfil de las personas mayores en Espana, 2011. Indicadores estadisticos basicos. Informes Portal Mayores, n 127; 2011 [acesso em 2 nov 2011]. Disponivel em: http:/www. imsersomayores.csic.es/ documentos/documentos/ pm-indicadoresbasicos11.pdf.

19. Garcia MAA, Yagi GH, Souza CS, Odoni APC, Frigério RM, Merlin SS. Atenção à saúde em grupos sob a perspectiva dos idosos. Rev LatinoAm Enfermagem [Internet] 2006 [acesso em 21 set 2011];14(2):175-82. Disponível em: http://dx.doi. org/10.1590/S0104-11692006000200005.

20. Yokoyama CE, Carvalho RS, Vizzotto MM. Qualidade de vida na velhice segundo a percepção de idosos freqüentadores de um centro de referência. Psicólogo inFormação 2006;10(10):57-82.

21. Cupertino APFB, Rosa FHM, Ribeiro PCC. Definição de envelhecimento saudável na perspectiva de indivíduos idosos. Psicol Reflex Crit 2007;20(1):81-6.

22. Silva I, Ribeiro JP, Cardoso H, Ramos H, Carvalhosa SF, Dias S, et al. Efeitos do apoio social na qualidade de vida, controle metabólico e desenvolvimento de complicações crônicas em indivíduos com diabetes. Psic, Saúde \& Doenças 2003;4(1):21-32.

23. Guedea MTD, Albuquerque FJB, Tróccolo BT, Noriega JAV, Seabra MAB, Guedea RLD. Relação do bem-estar subjetivo, estratégias de enfrentamento e apoio social em idosos. Psicol Reflex Crit 2006;19(2):301-8.

24. Bassoli S, Portella MR. Estratégias de atenção ao idoso: avaliação das oficinas de saúde desenvolvida em grupos de terceira idade no município de Passo Fundo - RS. Estud interdiscip Envelhec 2004;6:111-22.

25. Brandão JS. Lazer para o idoso ativo como fator de qualidade de vida no processo de envelhecimento [tese de Doutorado]. Porto Alegre: Instituto de Geriatria e Gerontologia da Pontifícia Universidade Católica do Rio Grande do Sul; 2009.

26. Garcia MAA, Yagi GH, Souza CS, Odoni APC, Frigério RM, Merlin SS. Atenção à saúde em grupos sob a perspectiva dos idosos. Rev LatinoAm Enfermagem [Internet] 2006 [acesso em 21 set 2011];14(2):175-82. Disponível em: http://dx.doi. org/10.1590/S0104-11692006000200005.

27. Francisco CM. Estudo dos fatores preditores de envelhecimento sem incapacidade funcional entre idosos em velhice avançada no município de São Paulo [dissertação de Mestrado]. São Paulo: Escola de Enfermagem da Universidade de São Paulo; 2006.

28. Rodrigues IG, Ruscalleda RMI. Satisfação com a vida e senso de autoeficácia para quedas em idosos. Rev Bras Clin Méd 2009;7:413-7. 